\title{
Susceptible conditions for debarking by deer in subalpine coniferous forests in central Japan
}

\author{
Hayato lijima ${ }^{*}$ (D) and Takuo Nagaike
}

\begin{abstract}
Background: Recently, deer have expanded their distribution to higher altitude ranges including subalpine forests. However, culling deer and construction of deer fence in subalpine forests are difficult because of steep slopes and complex topography. Thus it is necessary to clarify the factors which are associated with debarking by deer for the effective protection of subalpine forests. In this study, we examined which factors are associated with debarking by sika deer (Cervus nippon) in subalpine coniferous forests.

Methods: We conducted our survey in Minami-Alps National Park, central Japan. We established $2410 \mathrm{~m} \times 40 \mathrm{~m}$ plots and surveyed the occurrence of debarking on saplings $>30 \mathrm{~cm}$ in height and $<3 \mathrm{~cm}$ in diameter at breast height $(\mathrm{DBH})$ and on trees $>3 \mathrm{~cm}$ in $\mathrm{DBH}$, as well as sapling density within each plot. Minimum distances to nearest grassland of plots were calculated (tentatively assuming grassland would attract deer and would cause high debarking pressure in the surrounding subalpine forests).
\end{abstract}

Results: The mean percentage of debarked live saplings was higher than that of live trees. The mean percentage of debarked saplings which had already died was $81.6 \%$. Debarking of saplings increased with lower elevation, taller sapling size, and marginally increased near grassland. Sapling density was lower in plots with low basal area of conspecific trees near grassland and differed among species. Sapling density marginally decreased with decreasing elevation and increasing stand tree density. Debarking of trees was positively related to small DBH and low elevation, and marginally increased near grassland and differed among species.

Conclusions: Our results suggest that tall saplings in subalpine forests of low elevation or near subalpine grassland were susceptible to debarking by deer and monitoring of these areas may permit the early detection of the impacts of deer in subalpine coniferous forests.

Keywords: Abies, Cervus nippon, Debarking, Grassland, Picea, Sapling density, Subalpine region

\section{Background}

In recent years, the population densities of large ungulates, especially deer species, have increased worldwide (Stewart and Burrows 1989; Fuller and Gill 2001; Rooney 2001; Apollonio et al. 2010; Iijima et al. 2013). An increase of deer density has been shown to result in more prevalent debarking of trees (Akashi and Nakashizuka 1999; Nagaike and Hayashi 2003; Iijima and Nagaike 2015) and browsing of saplings and understory vegetation (Gill and Beardall 2001; Beguin et al. 2009; Suzuki

\footnotetext{
* Correspondence: hayato.iijima@gmail.com

Yamanashi Forest Research Institute, Saisyoji 2290-1, Fujikawa, Yamanashi 400-0502, Japan
}

\section{Springer}

(C) 2015 lijima and Nagaike. Open Access This article is distributed under the terms of the Creative Commons Attribution 4.0 International License (http://creativecommons.org/licenses/by/4.0/), which permits unrestricted use, distribution, and reproduction in any medium, provided you give appropriate credit to the original author(s) and the source, provide a link to the Creative Commons license, and indicate if changes were made. et al. 2013) in forests. To deal with the overabundance of deer and its effect on forest ecosystems, control of nuisance deer and the construction of fences to protect vegetation have been conducted. However, such countermeasures are difficult to perform in subalpine forests because of difficult access (e.g., steep slopes, complex topography, great distances from roads). Deer seasonally migrate to higher elevations, where delayed bud flush caused by low temperature provides fresh leaves even in mid-summer and they can escape from predators and more intense hunting pressure in low-elevation areas (Mysterud et al. 2011). These factors also have caused the number of deer in many higher elevation areas to 
increase (Takatsuki 2009), and debarking in subalpine forests has increased (Yokoyama et al. 2001; Takeuchi et al. 2011) in recent years. Therefore, factors correlated with debarking by deer in subalpine forests should be clarified to help effectively conserve these forests.

Many studies have examined the factors influencing debarking and browsing in lower elevation forests. Debarking was shown to depend on the size of trees (e.g., Nagaike and Hayashi 2003; Koda and Fujita 2011; Borkowski and Ukalski 2012), their species (e.g., Kay 1993; Akashi and Nakashizuka 1999; Moore et al. 1999; Takeuchi et al. 2011), proportion of coniferous stands (Ligot et al. 2013), the distance from forest road (McLaren et al. 2000), and snow depth (Iijima and Nagaike 2015). In addition to these factors, spatial variation of deer impact was observed in lower elevation forests: the higher the deer density, the higher the proportion of debarked trees (Iijima and Nagaike 2015) and browsed saplings (Akashi et al. 2011) and the lower the sapling density (Beguin et al. 2009). The spatial variation of deer density across low-elevation areas was explained by the presence of attractive habitat (e.g., artificial grassland; Kamei et al. 2010; Iijima et al. 2013). However, the attractive habitat in subalpine forests, which are located on steeper slopes and have more complex topography than lower elevation areas, has not been well studied.

Takeuchi et al. (2011) reported that elevation was an important factor affecting expansion of deer density into subalpine zones. In addition to elevation, the amount of attractive habitat (e.g., subalpine grassland) may affect deer density. Deer generally prefer herbaceous plants to woody plants (Takatsuki 1986; Winnie 2012), and severe browsing of herbaceous plants in subalpine grasslands by deer has been reported (Schütz et al. 2003; Nagaike 2012; Nagaike et al. 2014). Thus, subalpine forests which were surrounded by large subalpine grasslands would be more susceptible for debarking by deer. Thus far, however, direct evaluation of the relationship between these factors and the intensity of debarking in subalpine forest is rare.

The objective of this study was to clarify the conditions which are correlated with debarking by sika deer in subalpine forests in order to improve the effective management and conservation of these subalpine forests. We hypothesized that the occurrence of debarking and sapling density would increase and decrease in low altitude and abundant grassland.

\section{Methods \\ Study area}

The present study was conducted in subalpine forests in Minami-Alps National Park $\left(357.5 \mathrm{~km}^{2}\right)$ in central Japan (Fig. 1), where sika deer (Cervus nippon) density has been increasing in recent years (Izumiyama and Mochizuki 2008; Izumiyama et al. 2009). The park is characterized by steep slopes and a concentration of many mountains within a small area (Fig. 1). Subalpine coniferous forests dominate from 2000 to $2500 \mathrm{~m}$ elevation, mainly

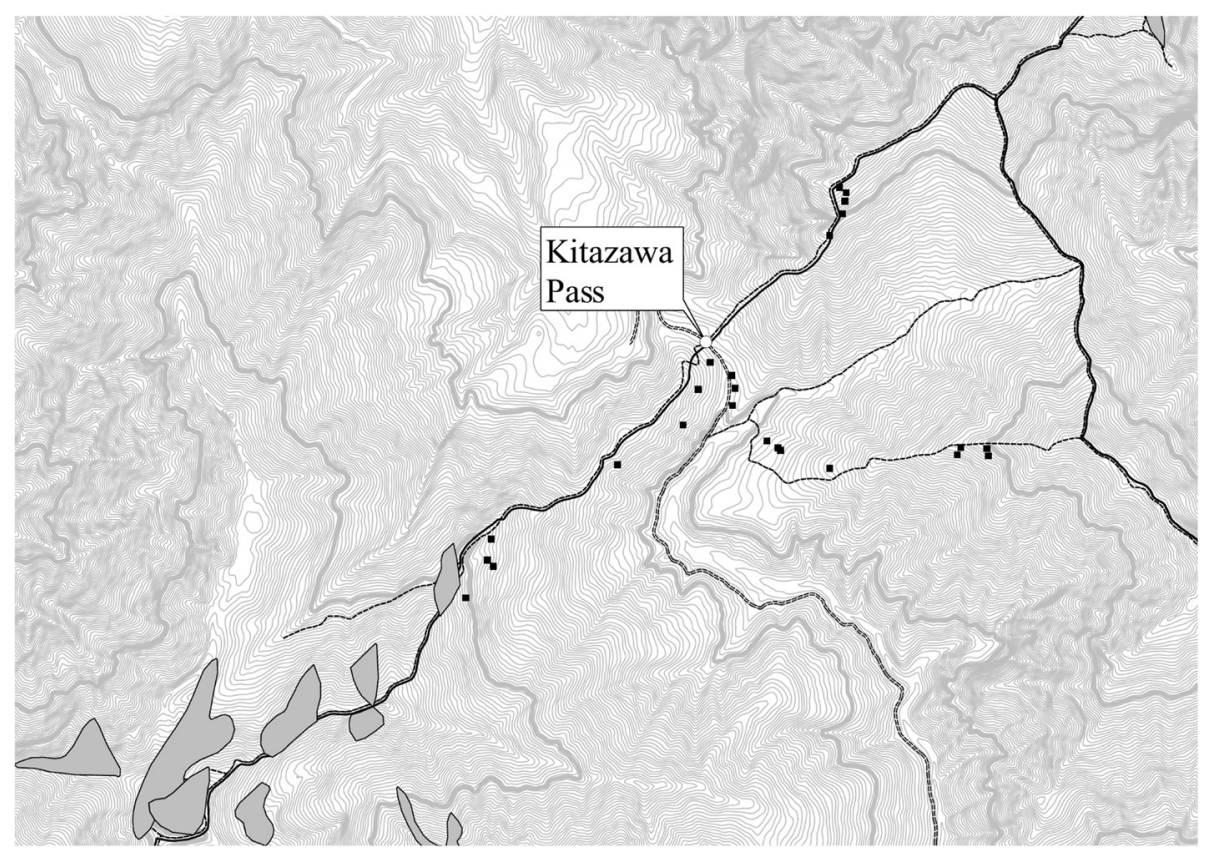

Fig. 1 Map of the study area. Gray polygons indicate the locations of subalpine grasslands (from the Natural Environment Information geographic information system provided by the Biodiversity Center of Japan: http://www.biodic.go.jp/trialSystem/top.html). Solid and dashed lines denote prefectural boundaries and trails, respectively. Solid squares indicate surveyed plots. This map was drawn by QGIS (QGIS Development 2015) 
composed of Abies mariesii, Abies veitchii, Picea jezoensis var. hondoensis, and Tsuga diversifolia (Fig. 2). Subalpine grasslands consisting of herbaceous species and dwarf tree community (Pinus pumila) are present at elevations higher than $2500 \mathrm{~m}$, and mixed conifer-broadleaf forests are present below $2000 \mathrm{~m}$. Sika deer are widely distributed in Japan. Their shoulder heights range from 90 to $190 \mathrm{~cm}$ and they have a highly varied diet (they eat graminoids in northern Japan and eat leaves and fruits in southern Japan; Ohdachi et al. 2009). They can reach bark and leaves up to ca. $2 \mathrm{~m}$ in height.

\section{Field surveys}

We established 24 rectangular plots (each of $10 \mathrm{~m} \times 40 \mathrm{~m}$ ) in natural coniferous forests at elevations of $2000 \mathrm{~m}$ (lowelevation zone) and $2500 \mathrm{~m}$ (high-elevation zone) and surveyed in September 2011 (Fig. 1). For all trees with the diameter at breast height $(\mathrm{DBH})>3 \mathrm{~cm}$ in the plots, we noted the species and measured DBH and the presence of debarking. Furthermore, for saplings survey, 8 subplots (each of $1 \mathrm{~m} \times 2 \mathrm{~m}$ ) were established at $10-\mathrm{m}$ intervals along the two long sides of each plot (8 subplots per a plot). Height and the occurrence of debarking on saplings $>30 \mathrm{~cm}$ in height and $<3 \mathrm{~cm}$ in $\mathrm{DBH}$ were measured and recorded in each subplot. In this study, we could not determine the timing of the occurrence of debarking and did not distinguish new and old debarking.

\section{The minimum distance from each plot to subalpine grassland}

The location of subalpine grassland in this region was obtained from the Natural Environment Information geographic information system (http://www.biodic.go.jp/ trialSystem/top.html, accessed 20 April 2015) provided by the Biodiversity Center of Japan (Fig. 1). The minimum distance from each plot to subalpine grassland was calculated by QGIS ver 2.8.1 (Quantum GIS Development 2015).

\section{Statistical analysis}

Sapling density and the occurrence of debarking of saplings and trees were analyzed using a generalized linear

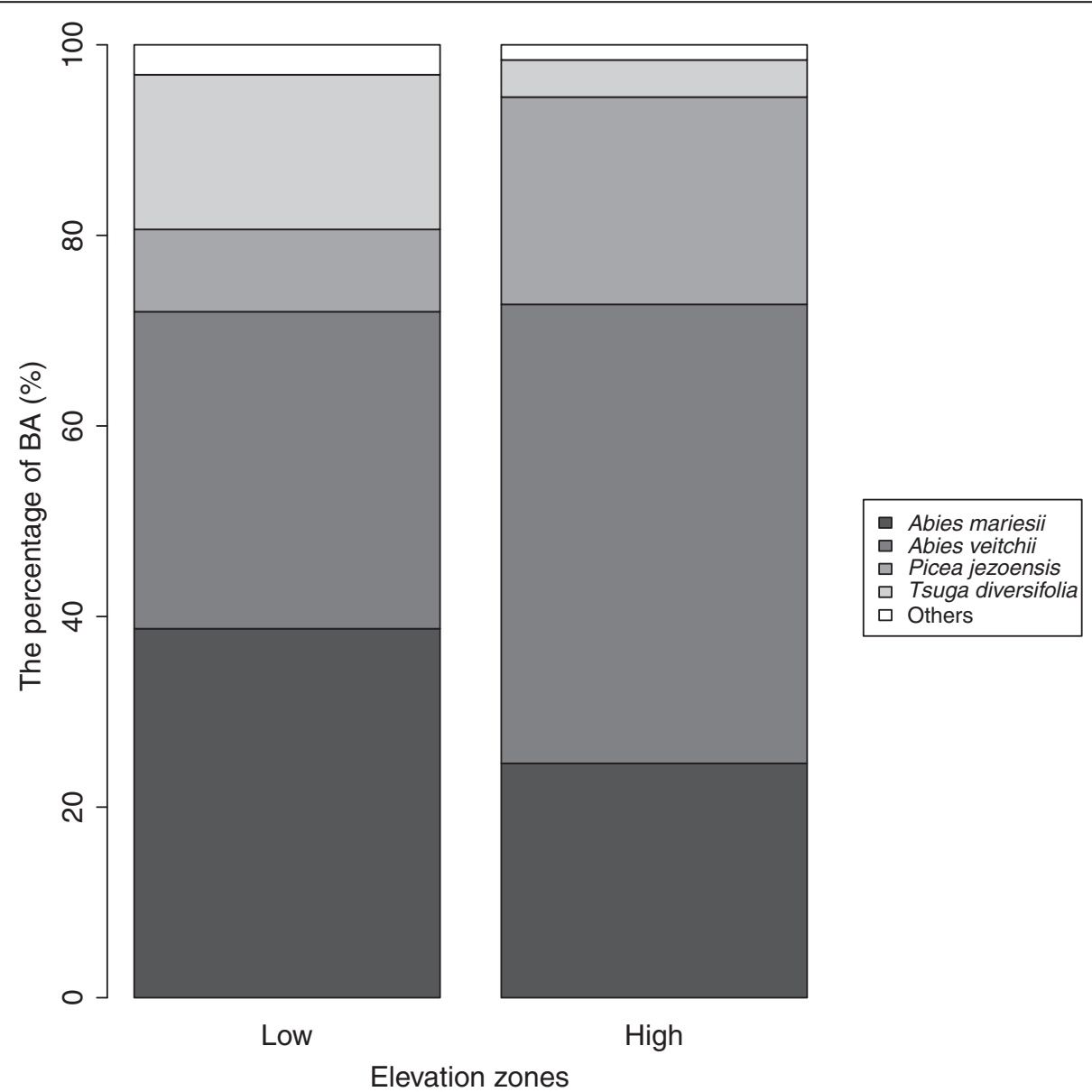

Fig. 2 Species composition of the dominant trees at low- and high-elevation zones. BA is basal area of trees at breast height. "Others" include Larix kaempferi, Betula corylifolia, Betula ermanii, Prunus maximowiczii, and Sorbus commixta 
mixed model (GLMM). For all models, we adopted each plot as random effect.

For analysis of sapling density, minimum distance from each plot to subalpine grassland, elevation zone, tree density in each plot (indicating understory light conditions), and species of each sapling were used as explanatory variables. We used the number of saplings as response variable. The means of the number of saplings and sapling density were equal because surveyed areas of the number of saplings were same for all plots. We also added basal area (BA) of conspecific trees (as an index of seed source) as an explanatory variable because the abundance of the seed source may affect sapling density. A Poisson distribution was adopted as the error distribution with a log-link function. Picea jezoensis was omitted from the species data because none of the surveyed individuals had been debarked, which made it impossible to estimate the coefficient.

For analysis of the occurrence of debarking of saplings, minimum distance from each plot to subalpine grassland, elevation zone, species, and sapling height were included as explanatory variables. A binomial distribution was adopted as the error distribution with a logit link function.

For analysis of the occurrence of debarking of trees, minimum distance from each plot to subalpine grassland, elevation zone, $\mathrm{DBH}$, and species were used as explanatory variables. A binomial distribution was adopted as the error distribution with a logit link function.

All analyses were conducted using $\mathrm{R}$ ver 3.1.3 (R Core Team 2015) and the glmmML package (Brostrom and Holmberg 2011). Model selection was performed using the Akaike information criterion (AIC, Akaike 1973) in conjunction with a backward elimination procedure. We determined that explanatory variables used in conjunction with all models which had delta AIC compared to the lowest $\mathrm{AIC}<2$ are significant and explanatory variable used in conjunction with any models which had delta AIC compared to the lowest AIC $<2$ are marginally significant. At the same time, we calculated Akaike weight (w) and the relative importance of variable (Burnham and Anderson 2002) for comparing the importance of each variable. Akaike weight is defined as

$$
w_{i}=\frac{\exp \left(-\frac{\Delta_{i}}{2}\right)}{\sum_{r=1}^{R} \exp \left(-\frac{\Delta_{i}}{2}\right)}
$$

where $\Delta_{i}=\mathrm{AIC}_{i}-\mathrm{AIC}_{\text {min }}$ is the difference between an AIC of each model and the minimum AIC among all candidate models (including null model and full model). This value, referred to as the Akaike weight, provides a relative weight of evidence for each model. The relative importance of predictor variable can be calculated as the sum of the Akaike weights over all of the models in
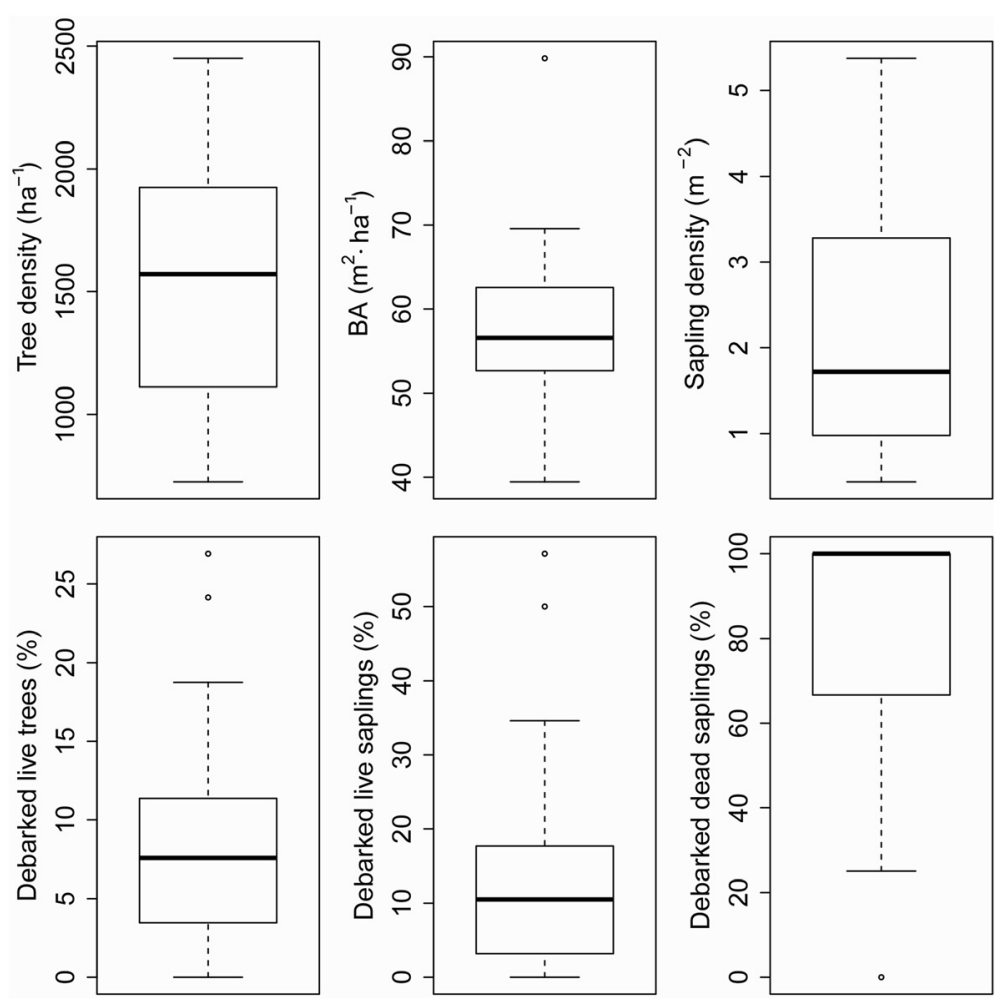

Fig. 3 Stand conditions 
Table $1 \mathrm{AIC}$ and coefficients of models which had $\triangle \mathrm{AIC}<2$ compared to the lowest AIC model for explaining the occurrence of debarking on saplings

\begin{tabular}{lccccc}
\hline AIC & A AIC & $\begin{array}{l}\text { Elevation zone } \\
2500 \mathrm{~m}\end{array}$ & Dist. grassland & Height of saplings & $\frac{\text { Species }^{\mathrm{b}, \mathrm{c}}}{\text { Abies veitchii }^{\text {Tsuga diversifolia }}}$ \\
\hline 398.028 & 0.000 & -2.634 & & 0.037 & \\
399.976 & 1.948 & -2.619 & $-1.269 \times 10^{-4}$ & 0.037 & \\
\hline
\end{tabular}

${ }^{a}$ Coefficient of elevation zone was calculated as a relative value when the coefficient of the low-elevation zone ( $2000 \mathrm{~m}$ ) was set to 0 . ${ }^{\mathrm{b}} \mathrm{Coefficient}$ of species was calculated as a relative value when the coefficient of Abies mariesii was set to 0 . ${ }^{C}$ Picea jezoensis was excluded from the analysis of saplings because no $P$. jezoensis saplings were debarked, so it was impossible to estimate the coefficient

which the parameter of interest appears. The relative importance range from 0 (least important) to 1 (most important).

\section{Results}

The percentages of debarked live trees differed among plots (Fig. 3). The differences among sapling types was large, with dead saplings being debarked at very high rates $($ mean $=81.6 \%$; Fig. 3 ).

Debarking of saplings was significantly related to a taller height of saplings and lower elevation zone, marginally related to minimum distance to grassland, and was not affected by species (Table 1). Sapling density significantly increased with increasing BA of conspecific trees and increasing minimum distance to grassland and marginally increased with increasing elevation and decreasing tree density (Table 2). Sapling density of $A$. mariesii was significantly higher than that of other species (Table 2). Debarking of trees was significantly related to small $\mathrm{DBH}$ and low elevation zone, and marginally decreased with long distance to grassland. Debarking of trees marginally differed by species (Table 3). Overall, Size of saplings and trees had strong effects on the occurrence of debarking (Table 4). Elevation zone, minimum distance to grassland, and species were marginal factors of the occurrence of debarking of saplings and trees and sapling density (Table 4).

\section{Discussion}

We showed the relationship between debarking of trees and saplings in subalpine coniferous forests and various factors. The percentages of debarked live saplings were higher than those of live trees, and the percentages for dead saplings were much higher than those for live saplings (Fig. 3). These results suggest that debarking by deer first occurs on saplings.

Tree and sapling sizes affected the occurrence of debarking but the effects of sizes showed opposite patterns for trees and saplings (Tables 1 and 3). Higher percentages of debarked small trees were also reported in many previous studies (Akashi and Nakashizuka 1999; Yokoyama et al. 2001; Nagaike and Hayashi 2003; Jiang et al. 2005; Kiffner et al. 2008; Takeuchi et al. 2011; Borkowski and Ukalski 2012), although the reasons were not clarified. One possibility for the selective debarking of small trees is the relative ease of debarking smaller trees (Ando et al. 2004). In contrast to trees, the relationship between sapling size and the occurrence of debarking has rarely been examined. Takatsuki and Gorai (1994) compared the size structure of trees between two distinct areas in Japan that differed in deer density. They showed that forests with high deer density lacked saplings $>90 \mathrm{~cm}$ in height, whereas there were abundant saplings shorter than $90 \mathrm{~cm}$ in forests both under high and low deer densities. In the present study, one reason for the low debarking intensity on small saplings (Table 1) is that they are more difficult to find than large saplings. Consequently, saplings $>30 \mathrm{~cm}$ in height and $<3 \mathrm{~cm}$ in DBH might be more susceptible to debarking by deer, suggesting that these might be a possible optimal size for debarking by sika deer.

$P$. jezoensis saplings appear to be less palatable for sika deer because no $P$. jezoensis saplings was debarked and we found marginal effect of species on debarking of trees (Table 3). Generally, Abies species were preferentially debarked over co-occurring Picea species (Heuze et al.

Table 2 AIC and coefficients of models which had $\triangle \mathrm{AIC}<2$ compared to the lowest AIC model for explaining sapling density

\begin{tabular}{|c|c|c|c|c|c|c|c|c|}
\hline \multirow[t]{2}{*}{$\overline{A I C}$} & \multirow[t]{2}{*}{$\triangle \mathrm{AIC}$} & \multirow{2}{*}{$\begin{array}{l}\text { Elevation zone }{ }^{a} \\
2500 \mathrm{~m}\end{array}$} & \multirow{2}{*}{$\begin{array}{l}\mathrm{BA}^{\mathrm{b}} \text { of conspecific } \\
\text { trees }\end{array}$} & \multirow[t]{2}{*}{ Dist. grassland } & \multicolumn{3}{|l|}{ Species $^{c}$} & \multirow[t]{2}{*}{ Tree density } \\
\hline & & & & & Abies veitchii & Picea jezoensis & $\overline{\text { Tsuga diversifolia }}$ & \\
\hline 1382.409 & 0.000 & & 0.048 & $9.310 \times 10^{-4}$ & -0.555 & -2.675 & $\begin{array}{l}-1.237 \\
\end{array}$ & \\
\hline 1382.624 & 0.214 & 0.745 & 0.048 & $9.561 \times 10^{-4}$ & -0.559 & -2.676 & -1.236 & -0.018 \\
\hline 1383.631 & 1.272 & 0.210 & 0.048 & $9.372 \times 10^{-4}$ & -0.557 & -2.680 & -1.239 & \\
\hline 1384.286 & 1.877 & & 0.048 & $9.311 \times 10^{-4}$ & -0.554 & -2.672 & -1.239 & -0.002 \\
\hline
\end{tabular}

${ }^{a}$ Coefficient of elevation zone was calculated as a relative value when the coefficient of the low-elevation zone (2000 m) was set to $0 .{ }^{b}$ BA, basal area. ${ }^{\mathrm{C}}$ Coefficient of species was calculated as a relative value when the coefficient of Abies mariesii was set to 0 
Table $3 \mathrm{AIC}$ and coefficients of models which had $\triangle \mathrm{AIC}<2$ compared to the lowest AIC model for explaining the occurrence of debarking on trees

\begin{tabular}{|c|c|c|c|c|c|c|c|}
\hline \multirow[t]{2}{*}{$\overline{A I C}$} & \multirow[t]{2}{*}{$\triangle \mathrm{AlC}$} & \multirow{2}{*}{$\begin{array}{l}\text { Elevation zone } \\
2500 \mathrm{~m}\end{array}$} & \multirow{2}{*}{$\begin{array}{l}\mathrm{DBH}^{\mathrm{b}} \text { of } \\
\text { trees }\end{array}$} & \multirow[t]{2}{*}{ Dist. grassland } & \multicolumn{3}{|l|}{ Species $^{\complement}$} \\
\hline & & & & & Abies veitchii & Picea jezoensis & Tsuga diversifolia \\
\hline 526.047 & 0.000 & -0.684 & -0.014 & $-4.146 \times 10^{-4}$ & & & \\
\hline 526.261 & 0.214 & -0.771 & -0.014 & $-4.196 \times 10^{-4}$ & 0.127 & -1.379 & -0.947 \\
\hline 527.907 & 1.856 & -0.592 & -0.014 & & & & \\
\hline 527.974 & 1.926 & -0.666 & -0.014 & & 0.076 & -1.453 & -0.959 \\
\hline
\end{tabular}

${ }^{a}$ Coefficient of elevation zone was calculated as a relative value when the coefficient of the low-elevation zone (2000 m) was set to $0 .{ }^{b} \mathrm{DBH}$, diameter at breast height. ${ }^{C}$ Coefficient of species was calculated as a relative value when the coefficient of Abies mariesii was set to 0

2005), and the different palatability among tree species suggests that deer debarking may alter the species composition of forests. However, P. jezoensis has been heavily debarked in some areas in Japan (Yokoyama et al. 2001; Ando et al. 2003), indicating that palatability of debarking may be affected by surrounding vegetation (Moore et al. 1999; McLaren et al. 2000). Therefore, P. jezoensis saplings at the sites examined in the present study may be debarked in the future if the deer density increases.

In addition to size and species as factors for debarking, elevation zones and grassland area also were associated with the damage to subalpine forests by deer. Low sapling density and high risk of debarking of trees and saplings were found in low elevation plots (Table 2). Other studies in Japan also found the intensities of debarking on trees and saplings in subalpine coniferous forests to be greater at lower elevations (Takeuchi et al. 2011). In our study area, sika deer migrate to highelevation areas in summer and to low-elevation areas from late autumn to late spring (Izumiyama and Mochizuki 2008) although there are some deer in low-elevation area even in summer. Then, opportunities of debarking for saplings and trees were larger in low-elevation zone than in high-elevation because deer stay longer time in low elevation-area than in high elevation-area. In addition to elevation, we found that the large subalpine grassland caused low sapling density (Table 2) and high risk of the occurrence of debarking of saplings and trees (Tables 1 and 3). Deer would likely be attracted to subalpine grassland because it has numerous herbaceous plants that serve

Table 4 Relative importance of variables in models

\begin{tabular}{llll}
\hline & $\begin{array}{l}\text { Debarking of } \\
\text { saplings }\end{array}$ & Sapling density & $\begin{array}{l}\text { Debarking of } \\
\text { trees }\end{array}$ \\
\hline Elevation zone & 1.000 & 0.506 & 0.785 \\
BA of conspecific species & Not included & 1.000 & Not included \\
DBH of trees & Not included & Not included & 1.000 \\
Dist. grassland & 0.274 & 1.000 & 0.674 \\
Height of saplings & 1.000 & Not included & Not included \\
Species & 0.137 & 1.000 & 0.463 \\
Tree density & Not included & 0.457 & Not included \\
\hline
\end{tabular}

as rich food sources (Takatsuki 1986; Winnie 2012). Trees and saplings in subalpine forests near subalpine grassland would be eaten by deer before sprout of grasses in early spring and after defoliation of grasses in late autumn. Some sika deer migrate to high-elevation area before sprout of grasses and after defoliation to escape the competition with other deer in low-elevation areas (Shin-ichiro Hamasaki, personal communication). Minimum distance to subalpine grassland, however, had only a marginal effect on the occurrence of debarking of saplings and trees (Tables 1 and 3). As the result of intensive debarking on saplings (Fig. 3), low sapling density near subalpine grassland occurred (Table 2) and then it might be obscure the relationship between the distance to grassland and the occurrence of debarking of saplings. In the future, the intensity of debarking of tree would increase if deer density remains at this level or increases.

\section{Conclusions}

Our analysis revealed that large saplings within the range of $30 \mathrm{~cm}$ in height and $3 \mathrm{~cm}$ in $\mathrm{DBH}$ in subalpine forests were most susceptible for debarking by sika deer. In addition to the size, saplings in low elevation zone or near subalpine grasslands were more susceptible to debarking by sika deer. This information may be useful to improve monitoring deer impact, or determining where to construct deer fences in the subalpine region. At the same time, deer population control in the subalpine region should be conducted in forests of low elevation zone or near subalpine grasslands.

\section{Competing interests}

This study was funded by the Comprehensive Research Organization for Science and Technology of Yamanashi Prefectural Government and Mitsui \& CO., LTD. The authors declare that they have no competing interests about non-financial aspects.

\section{Authors' contributions}

$\mathrm{HI}$ and TN substantially contributed about setting the experimental design and collecting data. $\mathrm{HI}$ and TN deeply discussed and approved the content of manuscript. Both authors read and approved the final manuscript. 


\section{Acknowledgements}

We thank Chiaki Ootsu for field assistance, as well as the staff of the

"Komorebi-sansou" mountain hut.

Received: 23 July 2015 Accepted: 20 December 2015

Published online: 23 December 2015

\section{References}

Akaike $H$ (1973) Information theory and an extension of the maximum likelihood principle, in 2nd International Symposium on Information Theory. Tsahkadsor, Armenian SSR, pp 267-281

Akashi N, Nakashizuka T (1999) Effects of bark-stripping by sika deer (Cervus nippon) on population dynamics of a mixed forest in Japan. For Ecol Manage 113:75-82

Akashi N, Unno A, Terazawa K (2011) Effects of deer abundance on broad-leaf tree seedling establishment in the understory of Abies sachalinensis plantations. J For Res 16:500-508

Ando M, Yokota H, Shibata E (2003) Bark stripping preference of sika deer, Cervus nippon, in terms of bark chemical contents. For Ecol Manage 177:323-331

Ando M, Yokota H, Shibata E (2004) Why do sika deer, Cervus nippon, debark trees in summer on Mt. Ohdaigahara, central Japan? Mamm Study 29:73-83

Apollonio M, Andersen R, Putman R (2010) European ungulates and their management in the 21st century. Cambridge University Press, NY.

Beguin J, Pothier D, Prévost M (2009) Can the impact of deer browsing on tree regeneration be mitigated by shelterwood cutting and strip clearcutting? For Ecol Manage 257:38-45

Borkowski J, Ukalski K (2012) Bark stripping by red deer in a post-disturbance area: the importance of security cover. For Ecol Manage 263:17-23

Brostrom G, Holmberg H (2011) Generalized linear models with clustered data: fixed and random effects models. Comput Stat Data Anal 55:3123-3134

Burnham KP, Anderson DR (2002) Model selection and multimodel inference: a practical information-theoretic approach, 2nd edn. Springer, New York

Fuller RJ, Gill RMA (2001) Ecological impacts of increasing numbers of deer in British woodland. Forestry 74:193-199

Gill RMA, Beardall V (2001) The impact of deer on woodlands: the effects of browsing and seed dispersal on vegetation structure and composition. Forestry 74:209-218

Heuze P. Schnitzlerm A, Klein F (2005) Consequences of increased deer browsing in winter on silver fir and spruce regeneration in the southern Vosges Mountains: implication for forest management. Ann For Sci 62:175-181

lijima H, Nagaike T, Honda T (2013) Estimation of deer population dynamics by Bayesian state-space model with multiple abundance indices. J Wildl Manage 77:1038-1047

lijima $\mathrm{H}$, Nagaike T (2015) Appropriate vegetation indices for measuring the impacts of deer on forest ecosystems. Ecol Ind 48:458-463

Izumiyama S, Mochizuki T (2008) Seasonal range use of sika deer, which inhabits the subalpine zone in the southern Japan Alps. Bull Shinshu Univ Alps Field Center 6:25-32 (in Japanese with English summary)

Izumiyama S, Mochizuki T, Takii A (2009) GPS tracking of Sika deer which inhabits the sub-alpine zone in the Southern Japan Alps. Bull Shinshu Univ Alps Field Center 7:63-71 (in Japanese with English summary)

Jiang Z, Ueda H, Kitahara M, Imaki H (2005) Bark stripping by sika deer on Veitch fir related to stand age, bark nutrition, and season in northern Mount Fuji district, central Japan. J For Res 10:359-365

Kamei T, Takeda K, Koh K, Izumiyama S, Watanabe O, Ohshima K (2010) Seasonal pasture utilization by wild sika deer (Cervus nippon) in a sown grassland. Grass Sci 56:65-70

Kay S (1993) Factors affecting severity of deer browsing damage within coppiced woodlands in the south of England. Biol Cons 63:217-222

Kiffner C, Rößiger E, Trisl O, Schulz R, Rühe F (2008) Probability of recent bark stripping damage by red deer (Cervus elaphus) on Norway spruce (Picea abies) in a low mountain range in Germany: a preliminary analysis. Silva Fennica 42:125-134

Koda R, Fujita N (2011) Is deer herbivory directly proportional to deer population density? Comparison of deer feeding frequencies among six forests with different deer density. For Ecol Manage 262:432-439

Ligot G, Gheysen T, Lehaire F, Hébert J, Licoppe A, Lejeune P, Brostaux Y (2013) Modeling recent bark stripping by red deer (Cervus elaphus) in South Belgium coniferous stands. Ann For Sci 70:309-318

McLaren BE, Mahoney SP, Porter TS, Oosenbrug SM (2000) Spatial and temporal patterns of use by moose of pre-commercially thinned, naturally-regeneration stands of balsam fir in central Newfoundland. For Ecol Manage 133:179-196
Moore NP, Hart JD, Langton SD (1999) Factors influencing browsing by fallow deer Dama dama in young broad-leaved plantations. Biol Cons 87:255-260

Mysterud A, Loe LE, Zimmermann B, Bischof R, Veiberg V, Meisingset E (2011) Partial migration in expanding red deer populations at northern latitudes: A role for density dependence? Oikos 120:1817-1825

Nagaike T, Hayashi A (2003) Bark-stripping by sika deer (Cervus nippon) in Larix kaempferi plantations in central Japan. For Ecol Manage 175:563-572

Nagaike T (2012) Effects of browsing by sika deer (Cervus nippon) on subalpine vegetation at Mt. Kita, central Japan. Ecol Res 27:467-473

Nagaike T, Ohkubo E, Hirose K (2014) Vegetation recovery in response to the exclusion of grazing by sika deer (Cervus nippon) in seminatural grassland on Mt. Kushigata, Japan. ISRN Biodiversity: Article ID 493495

Ohdachi SD, Ishibashi Y, Iwasa MA, Saitoh T (2009) The Wild Mammals of Japan. Shoukadoh Book Sellers, Kyoto

QGIS Development Team (2015) Quantum GIS Geographic Information System. Open Source Geospatial Foundation Project. http://qgis.osgeo.org

R Core Team (2015) R: A Language and Environment for Statistical Computing. R Foundation for Statistical Computing, Vienna, Austria, http://www.R-project.org/

Rooney TP (2001) Deer impacts on forest ecosystems: a North American perspective. Forestry 74:201-208

Schütz M, Risch AC, Leuzinger E, Krüsi BO, Achermann G (2003) Impact of herbivory by red deer (Cervus elaphus L.) on patterns and processes in subalpine grasslands in the Swiss National Park. For Ecol Manage 181:177-188

Stewart GH, Burrows LE (1989) The impact of white-tailed deer Odocoileus virginianus on regeneration in the coastal forests of Stewart Island, New Zealand. Biol Cons 49:275-293

Suzuki M, Miyashita T, Kabaya H, Ochiai K, Asada M, Kikvidze Z (2013) Deer herbivory as an important driver of divergence of ground vegetation communities in temperate forests. Oikos 122:104-110

Takatsuki S (1986) Food habits of sika deer on Mt. Goyo, northern Honshu. Ecol Res 1:119-128

Takatsuki S, Gorai T (1994) Effects of sika deer on the regeneration of a Fagus crenata forest on Kinkazan Island, northern Japan. Ecol Res 9:115-120

Takatsuki S (2009) Effects of sika deer on vegetation in Japan: a review. Biol Cons 142:1922-1929

Takeuchi T, Kobayashi T, Nashimoto M (2011) Altitudinal differences in bark stripping by sika deer in the subalpine coniferous forest of Mt. Fuji. For Ecol Manage 261:2089-2095

Winnie JAJ (2012) Predation risk, elk, and aspen: tests of a behaviorally mediated trophic cascade in the Greater Yellowstone Ecosystems. Ecology 93:2600-2614

Yokoyama S, Maeji I, Ueda T, Ando M, Shibata E (2001) Impact of bark stripping by sika deer, Cervus nippon, on subalpine coniferous forests in central Japan. For Ecol Manage 140:93-99

\section{Submit your manuscript to a SpringerOpen ${ }^{\circ}$ journal and benefit from:}

- Convenient online submission

- Rigorous peer review

- Immediate publication on acceptance

- Open access: articles freely available online

- High visibility within the field

- Retaining the copyright to your article

Submit your next manuscript at $>$ springeropen.com 